\title{
ANALISA PERBANDINGAN KURVA HAZARD PADA KOTA JAMBI \\ DENGAN MENGGUNAKAN BEBERAPA FUNGSI ATENUASI
}

\author{
Achmad Ja'far'), Alfin Aulia', Ig Imas Aryo C $\mathbf{P}^{3)}$ \\ 1).2),3) Mahasiswa Program Studi Teknik Sipil, Universitas Muhammadiyah Sorong
}

\begin{abstract}
ABSTRAK
Kota Jambi merupakan daerah yang rawan terhadap gempa bumi karena terdapat zona di daerah tersebut. Ancaman gempa bumi dari sesar ini tentunya dapat membahayakan daerah sekitar. Pada penelitian ini melakukan analisis kurva hazard untuk mengetahui berapa besar percepatan tanah (ground acceleration) yang terjadi akibat gempa bumi pada wilayah ini dengan berbagai macam jarak. Kurva hazard dianalisis menggunakan fungsi atenuasi (Patwardan dkk,1978, Crouse, 1987, Ambraseys,1990), Xiang\&Gao,1994). Hasil penelitian menunjukkan besarnya nilai percepatan tanah (ground acceleration) akan meningkat seiring dengan besarnya nilai jarak yang diperhitungkan. Kurva hazard pada daerah kota Jambi akan menunjukkan nilai terbesar pada saat menggunakan fungsi atenuasi Patwardan dkk, (1978) sedangkan yang terkecil adalah menggunakan fungsi atenuasi Crouse, (1987)
\end{abstract}

Kata Kunci : Kurva Hazard, Atenuasi, Kota Jambi.

\section{PENDAHULUAN}

Pulau Sumatera merupakan salah satu pulau di Indonesia yang berada di daerah pertemuan dua buah lempeng tektonik yaitu lempeng Indo-Australia yang berupa lempeng samudera dan lempeng Eurasia yang berupa lempeng benua. Adanya perbedaan massa jenis dari kedua lempeng tersebut dimana lempeng samudera lebih besar massa jenisnya daripada lempeng benua menyebabkan tipe pertemuan lempeng tersebut berupa subduksi.

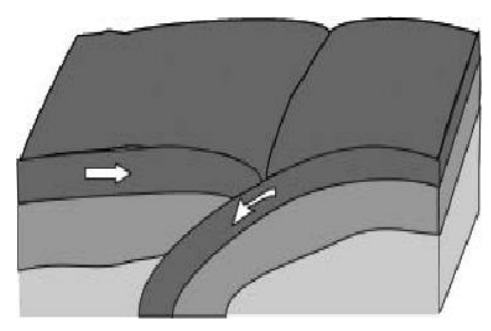

Gambar 1. Subduksi

Pertemuan kedua lempeng tersebut pada akhirnya mempengaruhi geomorfologi Pulau Sumatera. Penujaman lempeng samudera Indo-Australia menjadikan bagian barat Pulau 
Sumatera terangkat, sedangkan bagian timur relatif turun. Akibat dari penunjaman tersebut adalah terbentuknya rangkaian busur pulau depan (seperti: P. Simeulue, P. Banyak, P. Nias, P. Batu, P. Siberut hingga P. Enggano), rangkaian pegunungan Bukit Barisan dengan jalur vulkanik di tengahnya, serta sesar besar Sumetera (The Great Sumatera Fault) yang membelah Pulau Sumatera mulai dari Lampung hingga Banda Aceh dan terus hingga Burma.

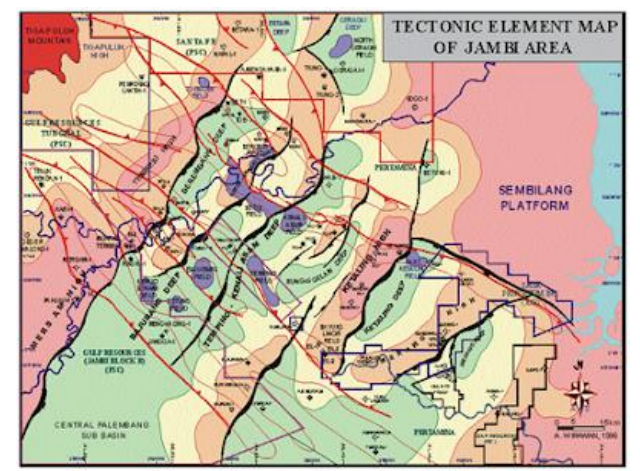

Gambar 2. Peta Element Tektonik Daerah Jambi

Sub Cekungan Jambi di Cekungan Sumatera Selatan adalah rangkaian half-graben berumur Paleogen yang berarah umum timurlaut - baratdaya, diantaranya adalah Tembesi high, Berembang depression, Sengeti-Setiti high, Tempino-Kenali Asam depression, Ketaling high, East Ketaling depression, Merang high, dan Merang depression (Gambar 1.2). Sub Cekungan Jambi memiliki dua pola struktur yang berbeda yaitu pola struktur berarah timurlautbaratdaya sebagai pengontrol pembentukan graben dan pengendapan Formasi Talang Akar dan pola struktur berarah baratlaut - tenggara yang berkaitan dengan tektonik kompresi dan menghasilkan sesar - sesar naik dan antiklin.

\section{PEMBAHASAN}

Ada beberapa metode yang dapat digunakan dalam Seismic Hazard Assessment untuk membuat prediksi kejadian gempa di masa yang akan datang (gempa rencana). Metodemetode itu diantaranya adalah The Gumbel Type I method, The Line Source Method, The Total Probability Area Method dan The EQ Occurrence Distributed.

Pada tugas kali ini, Seismic Hazard Assessment menggunakan The Line Source Method untuk membuat Hazard curve yang dapat memperkirakan kejadian gempa di Kota Jambi. Rumus Atenuasi yang digunakan adalah (Patwardan dkk,1978, Crouse, 1987, Ambraseys,1990, 
Xiang \& Gao,1994). Kota Jambi terletak pada koordinat $01^{\circ} 30^{\prime} 2.98^{\prime \prime}$ - 01 ${ }^{\circ} 7^{\prime} 1.07^{\prime \prime}$ Lintang Selatan, $103^{\circ} 40^{\prime} 1.67^{\prime \prime}-103^{\circ} 400.23^{\prime \prime}$ Bujur Timur.

\section{Metode}

Refensi dalam penelitian ini mengikuti Widodo (2012), Douglas (1991) dan Imam (2018). Untuk urutan metode yang digunakan dalam penelitian ini adalah sebagai berikut:

a. Mengidentifikasi koordinat kota Sorong.

b. Menganalisis jarak maks. 100km dari titik episenter gempa bumi yang akan terjadi.

e. Menganalisis percepatan tanah dengan menggunakan beberapa fungsi atenuasi

f. Membuat kurva hazard hasil dari analisis.

g. Kesimpulan

\section{Menghitung Fungsi Atenuasi}

Pada analisis resiko gempa apabila lokasi yang ditinjau (site interest) tidak mempunyai data rekaman gempa, maka untuk memperkirakan besarnya percepatan maksimum tanah digunakan fungsi atenuasi. Yang dimaksud dengan fungsi atenuasi adalah suatu fungsi yang menggambarkan korelasi antara intensitas (i) gerakan tanah setempat, magnitude (M) dan jarak (R) dari sumber titik dalam daerah sumber gempa. Memperkirakan fungsi atenuasi untuk gerakan tanah akibat gempa telah menjadi subjek yang menarik dalam penelitian bidang kegempaan. Fungsi atenuasi merupakan alat yang penting dalam mengaplikasikan resiko kegempaan dalam perencanaan bangunan tahan gempa. Faktor-faktor yang mempengaruhi fungsi atenuasi adalah :

1. Mekanisme Gempa

2. Jarak Episenter

3. Kondisi Tanah Lokal

\section{Fungsi Atenuasi Patwardan dkk,1978}

Rumus Atenuasi Patwardan :

$\operatorname{Ln} \mathrm{Y}=\operatorname{Ln}(157)+1.04 . \mathrm{Ms}-1.9 \cdot \operatorname{Ln}\left(\mathrm{R}+0.864 . \mathrm{e}^{0.463 \mathrm{Ms}}\right)$

Dimana : 
Y $\quad$ : Nilai percepatan tanah maksimum

Ms : Magnitude momen

$\mathrm{R} \quad$ : Jarak Hiposenter $(\mathrm{km})$

Perhitungan :

Menggunakan : $\quad$ Ms $=6.6$

$$
\begin{array}{ll}
\mathrm{R} & =1 \\
\mathrm{e} & =2.71828183
\end{array}
$$

$\operatorname{Ln} Y=\operatorname{Ln}(157)+1.04 \cdot 6 \cdot 6-1.9 \cdot \operatorname{Ln}\left(1+0.864 .2 .71828183^{0.463 \mathrm{Ms}}\right)$

$\mathrm{Y}=1870.45568$

Tabel 1.1. Contoh Hasil Perhitungan Atenuasi Patwardan

\begin{tabular}{|l|l|l|}
\hline No. & $\begin{array}{l}\mathrm{R} \\
(\mathrm{km})\end{array}$ & Y (Ground Acceleration) \\
\hline 1 & 1 & 1870.45568 \\
\hline 2 & 2 & 1562.248279 \\
\hline 3 & 3 & 1325.335776 \\
\hline 4 & 4 & 1139.185964 \\
\hline 5 & 5 & 990.1825895 \\
\hline 6 & 6 & 869.0016174 \\
\hline 7 & 7 & 769.0809613 \\
\hline 8 & 8 & 685.6917575 \\
\hline 9 & 9 & 615.3550936 \\
\hline 10 & 10 & 555.4646245 \\
\hline 11 & 11 & 504.0359303 \\
\hline 12 & 12 & 459.5361514 \\
\hline$\cdots$ & $\cdots$ & $\ldots$. \\
\hline$\cdots$ & $\cdots$ & $\ldots$. \\
\hline 100 & 100 & 20.19906672 \\
\hline & & \\
\hline
\end{tabular}


Berdasarkan persamaan tersebut diatas maka diperoleh kurva hazard seperti yang terlihat pada Gambar 2 berikut :

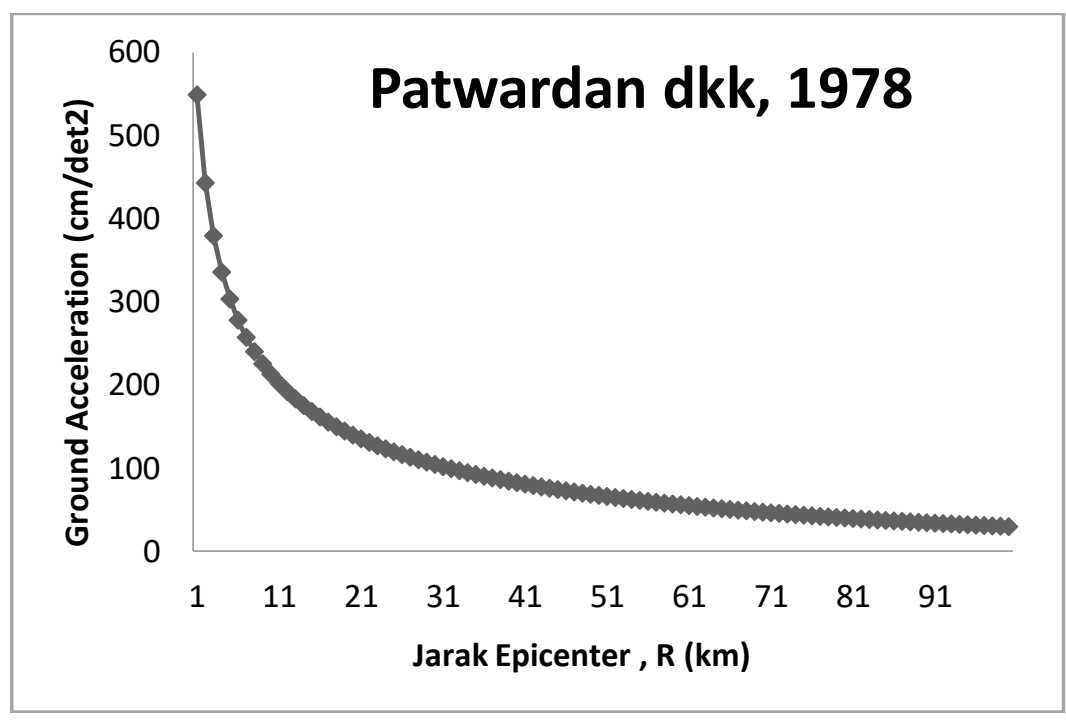

Fungsi Atenuasi Crouse, 1987

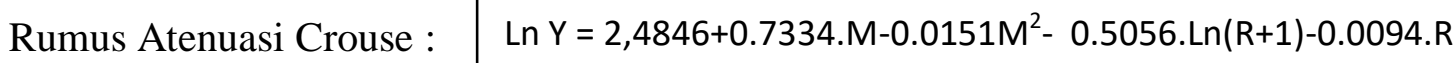

Dimana :

Y : Nilai percepatan tanah maksimum

M : Magnitude momen

R : Jarak Hiposenter $(\mathrm{km})$

Perhitungan :

Menggunakan : $\quad \mathrm{M}=6.6$

$$
\begin{aligned}
\mathrm{R} & =1 \mathrm{Km} \\
\mathrm{e} & =2.71828183
\end{aligned}
$$

$\operatorname{Ln} Y=2,4846+0.7334 .6 .6-0.01516 .6^{2}-0.5056 . \operatorname{Ln}(1+1)-0.0094 .1$

$$
\mathrm{Y}=548.6324819
$$


Berdasarkan persamaan tersebut diatas maka diperoleh kurva hazard seperti yang terlihat pada Gambar 3 berikut :

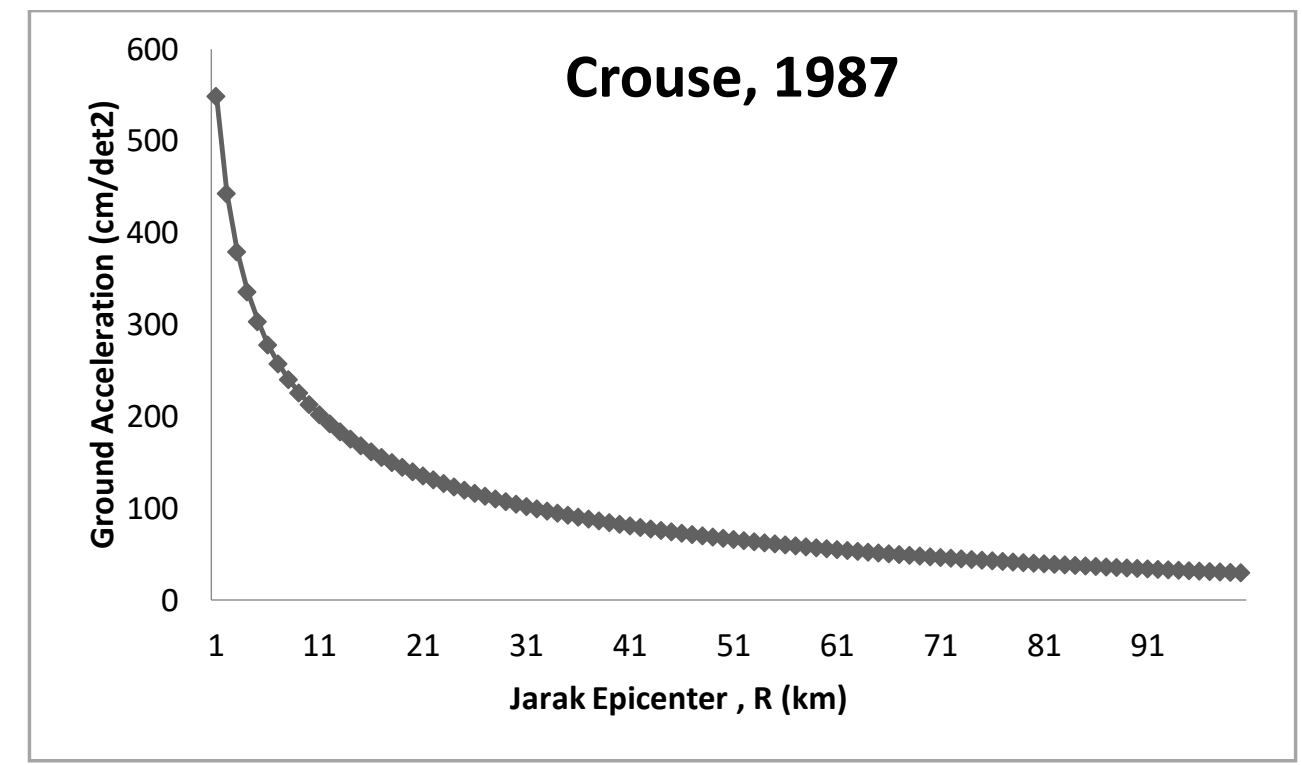

\section{Fungsi Atenuasi Xiang \& Gao,1994}

Rumus Atenuasi Campbell: $\mathrm{Y}=1291,07 . \mathrm{e} 0,5275 \mathrm{M}(\mathrm{R}+15)-1,5785$

Dimana :

$\begin{array}{ll}\mathrm{Y} & : \text { Nilai percepatan tanah maksimum } \\ \mathrm{M} & : \text { Magnitude momen } \\ \mathrm{R} & : \text { Jarak Hiposenter }(\mathrm{km})\end{array}$

Perhitungan :

Menggunakan : $\quad \mathrm{M} \quad=6.6$

$$
\begin{aligned}
\mathrm{R} & =1 \mathrm{Km} \\
\mathrm{e} & =2.71828183
\end{aligned}
$$

$\mathrm{Y}=1291,07 \cdot 2 \cdot 718282 \cdot 0,5275 \cdot 6 \cdot 6(1+15)-1,5785$

$Y=527.5245$ 
Berdasarkan persamaan tersebut diatas maka diperoleh kurva hazard seperti yang terlihat pada Gambar 4 berikut :

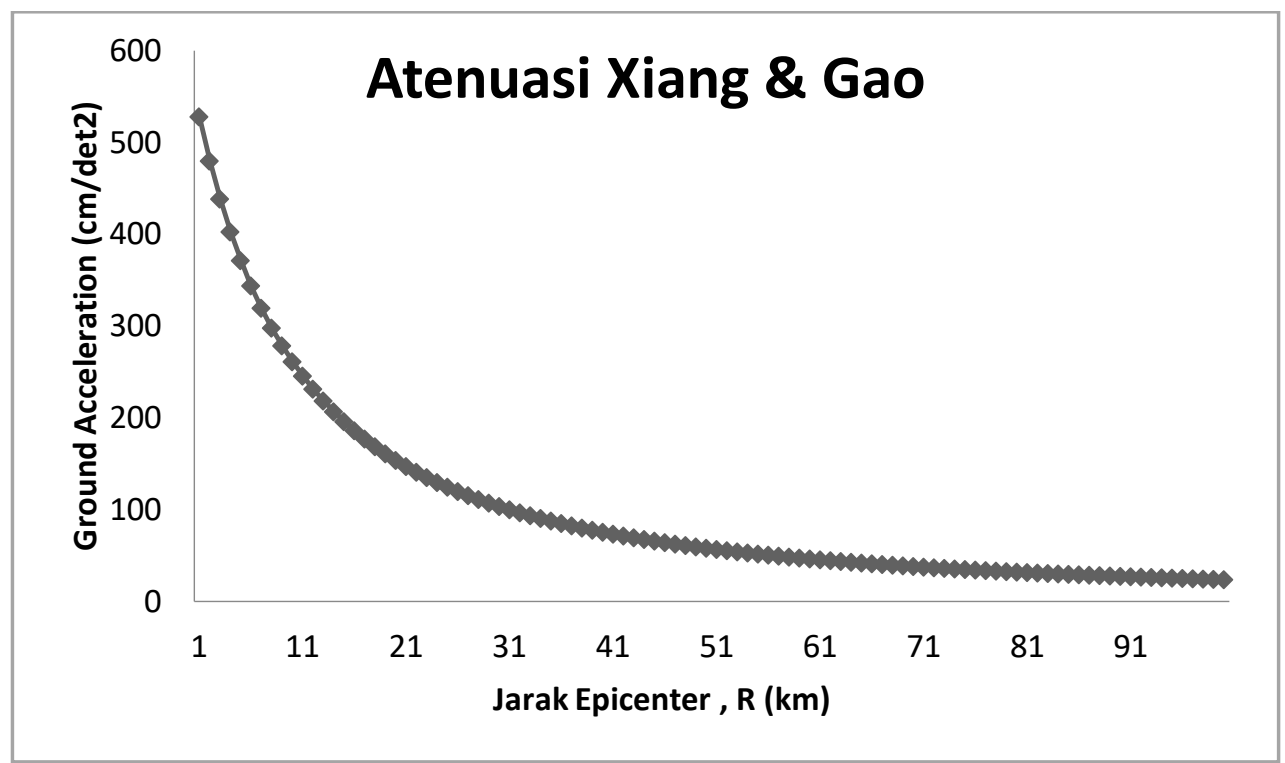

Fungsi Atenuasi Ambraseys (1990)

Rumus Atenuasi Ambraseys: $\log Y=-1,101+0,2615 . M w-\log r^{2}-0,00255 . r, \quad r=\left(R^{2}+7,2^{2}\right)^{0,5}$

Dimana :

$\begin{array}{ll}\mathrm{Y} & : \text { Nilai percepatan tanah maksimum } \\ \mathrm{M}_{\mathrm{w}} & : \text { Magnitude momen } \\ \mathrm{R} & : \text { Jarak Hiposenter }(\mathrm{km})\end{array}$

Perhitungan :

Menggunakan: $\quad \mathrm{M}=6.6$

$$
\begin{array}{ll}
\mathrm{R} & =1 \mathrm{Km} \\
\mathrm{E} & =2.71828183
\end{array}
$$

$\log Y=-1.101+0.2615 . M w-\log r^{2}-0.00255 . r$

$\log Y=-1.101+0.2615 \times 6.6-\log 1^{2}-0.00255 \times 1$

$\mathrm{Y}=0.076454131$ 
Berdasarkan persamaan tersebut diatas maka diperoleh kurva hazard seperti yang terlihat pada Gambar 5 berikut :

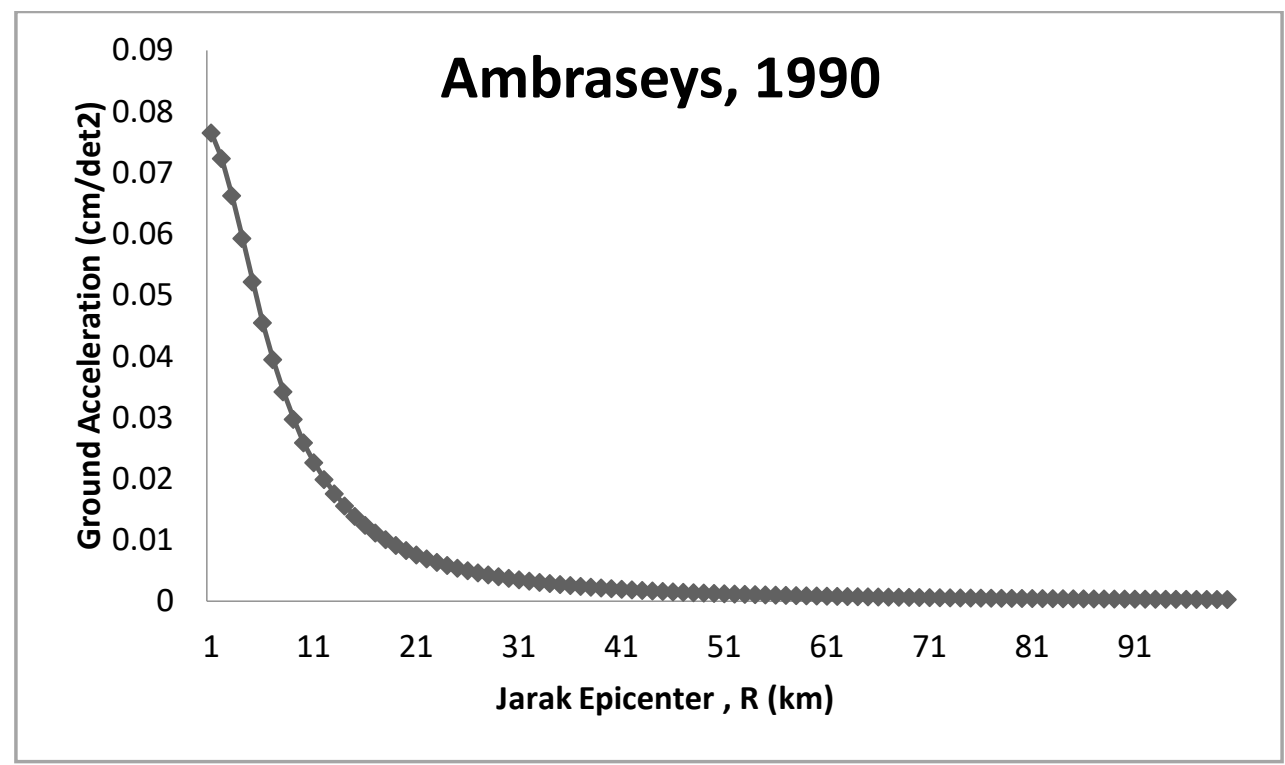

\section{Perbandingan Fungsi-Fungsi Atenuasi}

Setelah melakukan analisis dengan menggunakan fungsi atenuasi fungsi atenuasi (Patwardan dkk,1978, Crouse, 1987, Ambraseys,1990), Xiang \& Gao,1994) atas maka diperoleh hasil kurva hazard seperti yang tersaji pada Gambar 6 berikut ini.

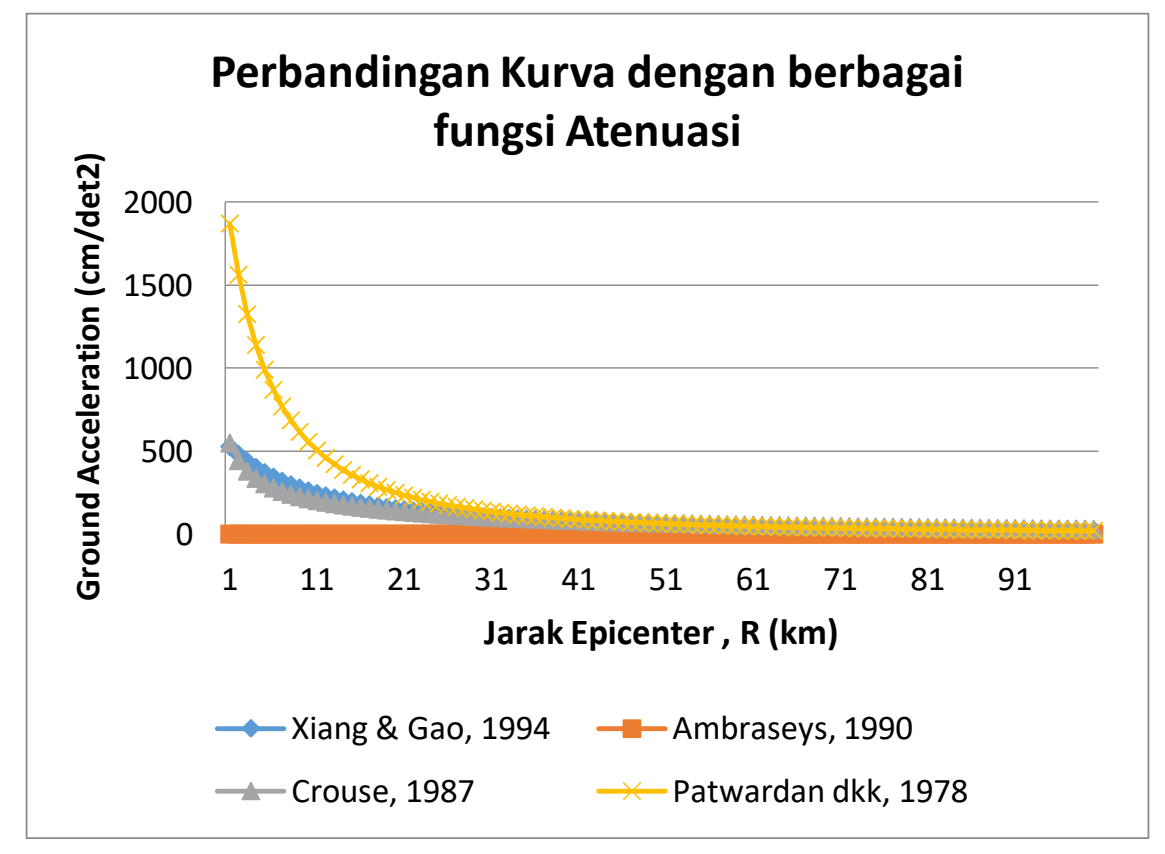


Berdasarkan hasil Gambar 6 di atas menunjukkan besarnya nilai percepatan tanah (ground acceleration) akan meningkat seiring dengan besarnya jarak yang diperhitungkan. Hasil penelitian menunjukkan bahwa kurva hazard menunjukkan nilai terbesar pada saat menggunakan fungsi atenuasi Patwardan dkk,1978 sedangkan nilai terkecil pada kurva hazard terjadi pada saat menggunakan fungsi atenuasi Crouse, 1987

Kurva hazard ini dapat digunakan dalam menentukan besarnya percepatan tanah di daerah kota Jambi yang disebabkan oleh sumber gempa sesar. Hal ini juga dapat dianggap sebagai langkah mitigasi. Upaya mitigasi perlu dilakukan untuk mengidentifikasi bencana yang akan terjadi dikemudian hari dengan mengambil langkah antisipasi. Hal ini dilakukan dalam rangka untuk mengurangi resiko yang ditimbulkan sehingga tingkat kerugian dan korban yang berjatuhan dapat diminimalisir.

\section{Kesimpulan}

Berdasarkan hasil penelitian maka diperoleh beberapa kesimpulan sebagai berikut ini:

1. Besarnya nilai percepatan tanah (ground acceleration) akan meningkat seiring dengan besarnya nilai jarak yang diperhitungkan.

2. Kurva hazard pada daerah kota Sorong akibat sesar akan menunjukkan nilai terbesar pada saat menggunakan fungsi atenuasi Patwardan dkk,1978

3. Kurva hazard pada daerah Sorong akibat sesar akan menunjukkan nilai terkecil pada saat menggunakan fungsi atenuasi Crouse, 1987

\section{Daftar pustaka}

1. Saputro, I. T. (2018, June 6). ANALISA PERBANDINGAN KURVA HAZARD PADA KOTA BANDA ACEH DENGAN SUMBER GEMPA SESAR SEULIMEN DAN MENGGUNAKAN BEBERAPA FUNGSI ATENUASI. https://doi.org/10.17605/0SF.IO/UVP2Y

2. Widodo, 2012, Seismologi Teknik \& Rekayasa Kegempaan, Pustaka Pelajar, Yogyakarta

3. Widodo, Atenuasi Gerakan Tanah dan Atenuasi Intensitas Gempa, Universitas Islam Indonesia, Yogyakarta 